Marquette University

e-Publications@Marquette

$1-2016$

\title{
Personality Characteristics and Experiential Avoidance in Trichotillomania: Results from an Age and Gender Matched Sample
}

Chad T. Wetterneck

Rogers Memorial Hospital

Eric B. Lee

Utah State University

Christopher A. Flessner

Kent State University

Rachel C. Leonard

Rogers Memorial Hospital

Douglas W. Woods

Marquette University, douglas.woods@marquette.edu

Follow this and additional works at: https://epublications.marquette.edu/psych_fac

Part of the Psychology Commons

\section{Recommended Citation}

Wetterneck, Chad T.; Lee, Eric B.; Flessner, Christopher A.; Leonard, Rachel C.; and Woods, Douglas W., "Personality Characteristics and Experiential Avoidance in Trichotillomania: Results from an Age and Gender Matched Sample" (2016). Psychology Faculty Research and Publications. 241.

https://epublications.marquette.edu/psych_fac/241 
Marquette University

e-Publications@Marquette

Psychology Faculty Research and Publications/College of Arts and Sciences

This paper is NOT THE PUBLISHED VERSION.

Access the published version at the link in the citation below.

Journal of Obsessive-Compulsive and Related Disorders, Vol. 8 (January 2016): 64-69. DOI. This article is (C) Elsevier and permission has been granted for this version to appear in e-Publications@Marquette. Elsevier does not grant permission for this article to be further copied/distributed or hosted elsewhere without the express permission from Elsevier.

\section{Personality Characteristics and Experiential Avoidance in Trichotillomania: Results from An Age and Gender Matched Sample}

Chad T. Wetterneck

Rogers Memorial Hospital

Eric B. Lee

Utah State University

Christopher A. Flessner

Kent State University

Rachel C. Leonard

Rogers Memorial Hospital

Douglas W. Woods

Texas A\&M University 


\section{Abstract}

Despite its prevalence and a growing body of research, significant gaps remain in the knowledge of trichotillomania (TTM). The current study sought to address this issue by examining personality characteristics, impulsivity, and experiential avoidance of those with TTM compared to an age and gender matched sample. 56 Female participants ( 28 with TTM and 28 non-clinical age-matched controls) completed the Personality Assessment Inventory (PAI), Barratt's Impulsivity Scale (BIS), and the Acceptance and Action Questionnaire (AAQ). Paired-sample $t$-tests compared each of the 28 individuals who met criteria for TTM to an age and gender matched individual who did not meet criteria for TTM or any Axis I condition. Significant differences were found between many of the PAI scales and subscales, impulsivity, and experiential avoidance. The TTM group displayed higher levels of pathology than the control group. The findings provide evidence that individuals with TTM demonstrate differing levels of personality characteristics compared to individuals without TTM and that treatment may benefit from acknowledging and targeting these areas.

\section{Keywords}

Trichotillomania, Personality, Impulsivity, Experiential, Avoidance

\section{Introduction}

Trichotillomania (TTM) is characterized by repetitive hair pulling, resulting in noticeable hair loss and significant distress or impairment (American Psychiatric Association American Psychiatric Association (2013). TTM is a noteworthy disorder, affecting approximately $1-3 \%$ of the population (Duke et al., 2009, Duke et al., 2010).

Woods, Wetterneck, and Flessner (2006) argue that despite a growing body of research, significant gaps remain in the knowledge of TTM and that much empirical work is needed to develop a better understanding of TTM and its treatment. The current study is an attempt to improve knowledge of TTM by examining personality and psychopathological characteristics in individuals with this disorder.

There has been limited research examining comorbid symptoms, personality variables, and psychological constructs (e.g., experiential avoidance (EA)) among individuals with TTM. Among this limited literature, three studies are of particular interest because they examine potential personality differences in those with TTM. The first study (Christenson, Chernoff-Clementz, \& Clementz, 1992) compared individuals with TTM to an age and gender-matched psychiatric control group and did not identify significant differences between the two groups in levels of personality disorders or traits. The second study (Hagh-Shenas, Moradi, Dehbozorgi, Farashbandi, \& Alishahian, 2004) compared 43 individuals with TTM to an age- and gender matched non-psychiatric control group on personality and psychological variables assessed by the Persian version of the NEO Personality Inventory-Revised (NEOPI-R). Results demonstrated that TTM participants scored higher on the anxiety, angry-hostility, depression, self-consciousness, impulsivity, and vulnerability to stress subscales and lower on the compliance subscale compared to the control group. The researchers noted that these personality characteristics resemble the results of individuals with borderline personality disorder. The third study (Keuthen et al., in press) compared 54 participants with TTM and 25 non-psychiatric controls using the NEO-Five Factor Inventory (NEO-FFI). Results indicated that higher neuroticism scores 
predicted a greater chance of TTM diagnosis. The researchers then utilized data from 164 participants with TTM to determine if NEO-FFI personality domains predicted TTM behavior, and found that lower levels of agreeableness and higher levels of neuroticism and openness were associated with greater pulling severity. Higher neuroticism was also associated with less control over hair pulling.

Taken together, these studies identified specific comorbid symptoms and traits as potentially playing an important role in TTM, including anxiety, depression, agreeableness, neuroticism, openness, angryhostility, self-consciousness, impulsivity, vulnerability to stress, and compliance. Two of the studies (Hagh-Shenas et al., 2004; Keuthen et al., in press), however, utilized the NEO-PI-R and NEO-FFI, which were not developed for use with individuals with psychopathology. Additionally, the NEO-PI-R and NEO-FFI lack validity scales, which are important in determining positive or negative response bias as well as general comprehension and consistency in responding. It is important, therefore, to conduct research on potential characteristics associated with TTM using measures normed with clinical populations and that include validity scales.

Of the aforementioned traits, impulsivity has long been thought to be associated with TTM and could potentially inform and enhance future treatment modalities (Chamberlain and Sahakian, 2007, Flessner et al., 2012). Despite the earlier classification of TTM as an impulse control disorder, there is a paucity of research on impulsivity and TTM, and extant research has notable limitations and disparate results. The Hagh-Shenas et al.'s finding of higher levels of impulsivity in TTM than control participants is interesting in light of ongoing speculation of the role of impulsivity in TTM. Some previous research has also identified higher impulsivity among individuals with TTM (Stein et al., 1995); however, others have not identified higher levels of impulsivity among individuals with TTM compared to non-clinical controls and individuals with OCD (Chamberlan, Fineberg, Blackwell, Robbins \& Sahakian, 2007).

Another trait-like construct emerging as an important factor in TTM is EA. EA is a behavioral repertoire defined by a tendency to minimize, avoid, or eliminate contact with unwanted private experiences and hypothesized as an underlying process in many disorders (Hayes, Wilson, Gifford, Follette, \& Strosahl, 1996). In TTM, EA may be attempts to produce short-term reductions in undesired feelings of anxiety, stress, or an "urge" through hair-pulling.

Researchers suggest EA is an important target in the treatment and maintenance of TTM, calling for further investigation (Begotka et al., 2004, Houghton et al., 2014, Twohig and Woods, 2004, Woods et al., 2006). Twohig and Woods (2004) found a moderate effect size in the reduction of EA in six adults with TTM treated with Acceptance and Commitment Therapy enhanced Habit Reversal (ACT/HR). Similarly, Woods et al. (2006) found a significant reduction of EA in 12 individuals treated with ACT/HR compared to a waitlist control group. EA has also been shown to mediate relationships between hair pulling severity and shame related cognitions, fear of negative evaluation, and dysfunctional beliefs about appearance (Norberg, Wetterneck, Woods, \& Conelea, 2007). Finally, another study found a significant relationship between EA and TTM severity in a large non-referred sample (Begotka et al., 2004). Thus, EA appears to play an important role in TTM. Further research into how EA impacts the development and maintenance of TTM symptoms, as well as how EA relates to other relevant constructs (i.e., anxiety, depression, emotion regulation, impulsivity) is needed. 
The current study aims to examine personality characteristics and EA among individuals with TTM compared to an age and gender matched paired sample. To address limitations of previous research, the current study will measure personality characteristics using the Personality Assessment Inventory (PAl; Morey, 1991), which provides a comprehensive, clinically-normed assessment of personality and psychopathology. We hypothesize that those with TTM will have elevated levels of anxiety, depression and borderline features as measured by PAI clinical scales compared to the control group. Moreover, we hypothesize that the treatment consideration scales of the PAI related to aggression and stress will be elevated compared to the control group. Furthermore, we posit that those with TTM will have greater levels of impulsivity and EA than the control group.

\section{Method}

\subsection{Participants and procedure}

Data from participants with TTM were collected in Woods et al. treatment study (2006). Of the 34 females who participated in that study, we found sex- and age-matched non clinical controls for 28 of them ( 20 were same-age matches; 8 were within 2 years) from two universities in the Midwest $(n=12)$ and Southwest $(n=16)$ United States. Data from the matched controls was gathered at the same time as the participants with TTM. All participants completed measures assessing TTM severity, impulsivity, personality characteristics, and EA. Demographic information is displayed in Table 1. Mean age was 33.04 (SD=9.04; range 18-50); ethnoracial background was $85.7 \%$ White, $7.1 \%$ Hispanic, and $7.2 \%$ other. The TTM group's mean age was 33.32 (SD=9.21; range 18-49). Ethnicity was 89.3\% Caucasian/White, 7.1\% Hispanic, and 3.6\% other. The control group's mean age was 32.75 (SD=9.03; range $18-50)$. Ethnicity was $82.1 \%$ Caucasian/White, $7.1 \%$ Hispanic, and $10.8 \%$ other. All participants received a diagnostic interview using the Structured Clinical Interview for DSM-IV Axis I Disorders (SCID-I) to assess for comorbid Axis I conditions. Individuals were excluded from the control group if they endorsed any conditions. The TTM group consisted of 11 participants who did not meet criteria for comorbid conditions. Of the remaining 17 TTM group participants, 13 met criteria for one, three met criteria for two, and one met criteria for four comorbid conditions. Comorbid diagnoses included major depressive disorder $(n=7)$, substance use disorder $(n=6), \operatorname{OCD}(n=4)$, mood disorder NOS $(n=3)$, specific phobia $(n=2)$, panic disorder $(n=1)$, and social phobia $(n=1)$. Independent sample $t$-tests comparing age, and scores on each of the measures (including all PAI scales) of participants without verses with comorbidity revealed only one significant difference, on the PAI Drug Use Scale $(p=.04$; Non-comorbid group mean=46.3 (3.5), comorbid group=50.8 (7.4).

Table 1. Participant age, ethnicity, and rates of comorbidity.

\begin{tabular}{|l|l|l|l|}
\hline & TTM $(\boldsymbol{n}=\mathbf{2 8})$ & Non-TTM $(\boldsymbol{n}=\mathbf{2 8})$ & Total $(\boldsymbol{n}=\mathbf{5 6})$ \\
\hline Mean age & $33.32(9.21)$ & $32.75(9.03)$ & $33.04(9.04)$ \\
\hline Ethnicity & & & \\
\hline White & $89.3 \%(25)$ & $82.1 \%(23)$ & $85.7 \%(48)$ \\
\hline Hispanic & $7.1 \%(2)$ & $7.1 \%(2)$ & $7.1 \%(4)$ \\
\hline Other & $3.6 \%(1)$ & $10.8 \%(3)$ & $7.2 \%(4)$ \\
\hline Secondary diagnoses & & & \\
\hline Substance use disorder & $21.4 \%(6)$ & - & - \\
\hline Major depressive disorder & $25.0 \%(7)$ & - & - \\
\hline
\end{tabular}




\begin{tabular}{|l|l|l|l|}
\hline Obsessive-compulsive disorder & $14.3 \%(4)$ & - & - \\
\hline Mood disorder NOS & $10.7 \%(3)$ & - & - \\
\hline Specific phobia & $7.1 \%(2)$ & - & - \\
\hline Panic disorder & $3.6 \%(1)$ & - & - \\
\hline Social phobia & $3.6 \%(1)$ & - & - \\
\hline No comorbid condition & $39.3 \%(11)$ & $100 \%(28)$ & - \\
\hline One comorbid condition & $46.4 \%(13)$ & - & - \\
\hline Two comorbid conditions & $10.7 \%(3)$ & - & - \\
\hline Four comorbid conditions & $3.6 \%(1)$ & - & - \\
\hline
\end{tabular}

\section{Measures}

Massachusetts General Hospital Hair-pulling Scale (MGH-HS; Keuthen et al., 1995). A seven-item selfreport scale assessing hair-pulling severity with questions about the urge to pull, actual hair-pulling, and consequences of pulling. Scores range from 0 to 28; higher scores reflect greater hair-pulling severity. The MGH-HS displays good psychometric properties.

Personality Assessment Inventory (PAI; Morey, 1991). A 344-item self-report scale assessing psychopathology and other areas of clinical interest. Items are rated on a four-point scale (i.e., not at all true, slightly true, mainly true, and very true). The PAI contains 22 non-overlapping full scales including: four validity scales, 11 clinical scales (10 have individual subscales), five treatment scales, and two interpersonal scales. All scales have a mean $T$-score of 50 with a standard deviation of 10. The PAI displays good psychometric properties.

Barratt's Impulsivity Scale (BIS-11: Patton, Stanford, \& Barratt, 1995). A 30-item scale assessing impulsiveness. Items are rated on a four-point scale (i.e., rarely/never, occasionally, often, almost always/always). Scores range from 30 to 120, with higher scores reflecting greater levels of impulsiveness. The BIS-11 displays good psychometric properties.

Acceptance and Action Questionnaire (AAQ; Hayes et al., 2004). A nine-item scale designed to measure EA. Items are rated on a seven-point Likert scale (i.e., 1=never true, 7=always true). Scores range from 9 to 56 , with higher scores reflecting greater levels of EA. The AAQ displays adequate psychometric properties.

\section{Data analysis}

Data were analyzed using SPSS 20.0 software. Independent-samples $t$-tests were conducted comparing the TTM group to the non-TTM group with regard to personality, impulsivity, and EA. Associations between hair pulling severity and personality characteristics, EA, and impulsivity in the TTM group were then examined. First, Pearson's correlations were performed between each of the variables. Second, a multiple linear regression was conducted utilizing variables that were significantly correlated to hair pulling severity as independent variables and hair pulling severity as the dependent variable. Due to the large number of tests performed and the resulting increased probability of type 1 errors, results with $p$ values greater than .01 were not considered significant. Additionally, effect sizes were examined to describe the magnitude of potential differences. 


\section{Results}

Mean MGH-HS, BIS, and AAQ scores are displayed in Table 2, along with $T$-scores for variables compared across groups (i.e., all except MGH-HS, which was only given to the TTM group). The mean MGH-HS score for the TTM group was indicative of clinical levels of hair-pulling. The TTM and control groups significantly differed $(p \leq .01)$ on the the AAQ and BIS. The higher AAQ scores for the TTM group indicates higher levels of EA than the non-TTM group. Finally, the higher BIS scores for the TTM group indicate higher levels of impulsivity.

Table 2. Mean scores and paired T-scores for MGH-HS, AAQ, and BIS.

\begin{tabular}{|l|l|l|l|l|l|l|}
\hline Measure & $\begin{array}{l}\text { TTM } \\
\text { mean }\end{array}$ & $\begin{array}{l}\text { Non-TTM } \\
\text { mean }\end{array}$ & Paired t-test & 95\% C.I. lower & 95\% C.I. upper & Cohen's $\boldsymbol{d}$ \\
\hline MGH-HS & 17.29 & - & - & - & - & - \\
\hline AAQ & 38.21 & 31.43 & $2.91^{* *}$ & 2.11 & 11.46 & .78 \\
\hline BIS & 71.79 & 63.46 & $3.00^{* *}$ & 2.75 & 13.89 & .80 \\
\hline
\end{tabular}

$d f=54$.

${ }^{*} p<.05$.

${ }^{* *} p<.01$.

Mean scores and paired $T$-scores for PAI scales are displayed in Table 3. Significant differences between the groups were found on: Anxiety (Cognitive, Affective, and Physiological), Anxiety Related Disorders (Obsessive-Compulsive), Depression (Cognitive and Affective), Borderline Features (Affective Instability), and Aggression (Aggressive Attitude and Physical Aggression). Scores for the TTM group were significantly higher for each of the subscales than the non-TTM group's scores, indicating higher levels of psychopathology. The TTM and control groups significantly differed $(p \leq .01)$ on the Negative Impression Management (NIM), Stress, and Treatment Rejection scales of the PAI. The higher NIM and Stress scores indicate that the TTM group reported greater levels of perceived life difficulty as well as a more pessimistic worldview than the non-TTM group. The lower Treatment Rejection score indicates that the TTM group is more open to treatment and motivated to change than the non-TTM group.

Table 3. Mean scores and paired T-scores for PAl scales.

\begin{tabular}{|l|l|l|l|l|l|l|}
\hline PAI scale & $\begin{array}{l}\text { TTM } \\
\text { mean }\end{array}$ & $\begin{array}{l}\text { Non-TTM } \\
\text { mean }\end{array}$ & $\begin{array}{l}\text { Paired } \text { - } \\
\text { test }\end{array}$ & $\begin{array}{l}\text { 95\% C.I. } \\
\text { lower }\end{array}$ & $\begin{array}{l}\text { 95\% C.I. } \\
\text { upper }\end{array}$ & Cohen's $\boldsymbol{d}$ \\
\hline Somatic complaints & 50.46 & 46.36 & $2.22^{*}$ & .39 & 7.82 & .59 \\
\hline Conversion & 48.39 & 45.25 & $2.64^{*}$ & .76 & 5.53 & .71 \\
\hline Somatization & 49.32 & 45.39 & $2.32^{*}$ & .54 & 7.32 & .62 \\
\hline Health concerns & 51.79 & 47.25 & n.s. & -.06 & 9.14 & .53 \\
\hline Anxiety & 58.71 & 50.86 & $2.55^{*}$ & 1.68 & 14.04 & .68 \\
\hline Cognitive & 60.93 & 50.64 & $3.36^{* *}$ & 4.14 & 16.43 & .90 \\
\hline Affective & 58.39 & 48.36 & $3.77^{* *}$ & 4.70 & 15.37 & 1.01 \\
\hline Physiological & 54.86 & 48.50 & $2.92^{* *}$ & 2.00 & 10.72 & .78 \\
\hline Anxiety related disorders & 57.46 & 49.36 & $2.90^{* *}$ & 2.51 & 13.71 & .78 \\
\hline Obsessive-compulsive & 58.32 & 48.75 & $3.52^{* *}$ & 4.12 & 15.02 & .94 \\
\hline Phobias & 54.36 & 49.04 & $2.32^{*}$ & .71 & 9.93 & .62 \\
\hline Traumatic stress & 54.86 & 48.57 & n.s. & -.40 & 12.98 & .50 \\
\hline
\end{tabular}




\begin{tabular}{|c|c|c|c|c|c|c|}
\hline Depression & 56.93 & 47.00 & $4.09^{* *}$ & 5.07 & 14.79 & 1.09 \\
\hline Cognitive & 56.82 & 46.00 & $3.73^{* *}$ & 5.01 & 16.63 & 1.00 \\
\hline Affective & 56.79 & 46.36 & $3.98^{* *}$ & 5.17 & 15.68 & 1.06 \\
\hline Physiological & 50.14 & 48.82 & n.s. & -2.27 & 4.91 & .20 \\
\hline Mania & 49.07 & 47.07 & n.s. & -3.69 & 7.89 & .19 \\
\hline Activity level & 47.46 & 43.57 & n.s. & -1.04 & 8.82 & .42 \\
\hline Grandiosity & 47.39 & 47.29 & n.s. & -5.02 & 5.23 & .01 \\
\hline Irritability & 52.29 & 45.79 & $2.55^{*}$ & 1.38 & 11.62 & .68 \\
\hline Paranoia & 49.32 & 47.96 & n.s. & -4.24 & 6.96 & .13 \\
\hline Hypervigilance & 45.32 & 47.68 & n.s. & -7.65 & 2.94 & .24 \\
\hline Persecution & 46.29 & 45.11 & n.s. & -2.38 & 4.73 & .18 \\
\hline Resentment & 49.07 & 47.07 & n.s. & -3.66 & 7.66 & .19 \\
\hline Schizophrenia & 48.89 & 45.39 & n.s. & -1.10 & 8.10 & .41 \\
\hline Psychotic experiences & 43.71 & 43.00 & n.s. & -2.86 & 4.29 & .11 \\
\hline Social detachment & 48.46 & 46.79 & n.s. & -3.14 & 6.49 & .19 \\
\hline Thought disorder & 52.11 & 46.75 & $2.21^{*}$ & .50 & 10.21 & .59 \\
\hline Borderline features & 58.32 & 48.86 & $3.06^{* *}$ & 3.26 & 15.67 & .82 \\
\hline Affective instability & 58.50 & 47.68 & $3.87^{* *}$ & 5.22 & 16.42 & 1.04 \\
\hline Identity problems & 57.46 & 50.50 & $2.58^{*}$ & 1.54 & 12.39 & .69 \\
\hline Negative relationships & 52.43 & 48.04 & n.s. & -1.68 & 10.47 & .39 \\
\hline Self-harm & 48.43 & 45.93 & n.s. & -2.59 & 7.59 & .26 \\
\hline Antisocial features & 49.68 & 48.43 & n.s. & -3.85 & 6.35 & .13 \\
\hline Antisocial behaviors & 46.14 & 47.21 & n.s. & -4.69 & 2.55 & .16 \\
\hline Egocentricity & 49.43 & 45.82 & $2.02^{*}$ & .03 & 7.18 & .54 \\
\hline Stimulus seeking & 47.14 & 51.07 & $-2.08 *$ & -7.71 & -.14 & .56 \\
\hline Aggression & 51.07 & 43.93 & $2.97^{* *}$ & 2.32 & 11.97 & .79 \\
\hline Aggressive attitude & 51.43 & 42.86 & $2.96^{* *}$ & 2.77 & 14.38 & .79 \\
\hline Verbal aggression & 49.29 & 46.75 & n.s. & -2.83 & 7.90 & .25 \\
\hline Physical aggression & 51.25 & 44.61 & $3.92^{* *}$ & 3.24 & 10.04 & 1.05 \\
\hline Inconsistency & 47.14 & 49.64 & n.s. & -8.31 & 3.31 & .23 \\
\hline Infrequency & 49.79 & 49.32 & n.s. & -4.16 & 5.09 & .05 \\
\hline $\begin{array}{l}\text { Negative impression } \\
\text { management }\end{array}$ & 54.07 & 47.93 & $3.10^{* *}$ & 2.17 & 10.12 & .83 \\
\hline $\begin{array}{l}\text { Positive impression } \\
\text { management }\end{array}$ & 46.75 & 49.43 & n.s. & -9.63 & 4.27 & .21 \\
\hline Alcohol problems & 52.43 & 51.36 & n.s. & -4.19 & 6.33 & .11 \\
\hline Drug problems & 49.04 & 47.79 & n.s. & -2.25 & 4.75 & .19 \\
\hline Suicidal ideation & 53.89 & 48.96 & $2.26^{*}$ & .56 & 9.29 & .61 \\
\hline Stress & 54.50 & 47.25 & $2.77^{* *}$ & 2.00 & 12.50 & .74 \\
\hline Nonsupport & 49.07 & 44.86 & n.s. & -.71 & 9.14 & .46 \\
\hline Treatment rejection & 40.50 & 54.04 & $-5.04^{* *}$ & -18.92 & 8.15 & 1.35 \\
\hline Dominance & 47.93 & 50.71 & n.s. & -8.21 & 2.64 & .28 \\
\hline Warmth & 53.36 & 52.86 & n.s. & -4.31 & 5.31 & .06 \\
\hline
\end{tabular}

$d f=54$. 
${ }^{*} p<.05$.

${ }^{* *} p<.01$.

Only the AAQ and PAI Anxiety Related Disorders (Traumatic Stress; PAI-ARD-TS) were significantly correlated with MGH-HS scores. Pearson's $r$ as well as results from the linear regression are displayed in Table 4. The results of the regression indicate that scores on the PAI-ARD-TS scale significantly predicted MGH-HS scores $(B=.46, t(2)=2.25, p=.036)$ while AAQ scores did not $(B=.21, t(2)=1.05, p=.307)$.

Table 4. Multiple regression predicting MGH-HS scores from AAQ and PAI anxiety related disorders (traumatic stress) scores.

\begin{tabular}{|l|l|l|l|l|}
\hline & $\boldsymbol{B}$ & S.E. & $\boldsymbol{B}$ & Pearson $\boldsymbol{r}$ \\
\hline Constant & 2.95 & 4.65 & & \\
\hline AAQ & .12 & .12 & .21 & .42 \\
\hline ARDTS* & .17 & .08 & .46 & .48 \\
\hline
\end{tabular}

$R^{2}=.34$.

${ }^{*} p<.05$.

\section{Discussion}

The present study examined the differences between individuals with TTM and a gender- and agematched control group on personality characteristics and psychopathology. The findings indicate that the TTM group was significantly different than the control group in a number of important areas, including EA, impulsivity, as well as a number of personality and psychopathology characteristics. Of note, although significant differences were found between the TTM and control group with regard to the PAI scales, none of the scales were significantly elevated above the PAI norms indicating that the TTM group had no personality characteristics in the clinically severe range. Overall, the findings largely corroborate the results of other studies of personality and TTM (Christenson et al., 1992, Hagh-Shenas et al., 2004; Keuthen et al., in pres s) and provide valuable insight into TTM that may inform future research and treatment of this condition.

The TTM group scored significantly higher, with a medium effect size, on impulsivity compared to the control group. This finding, while not entirely surprising, contributes to the growing literature on the relationship between impulsivity and TTM and the importance of recognizing and targeting it in treatment. While current treatments for TTM recognize the presence of impulsivity in those with TTM, further strides to target this important construct may be beneficial when developing future treatments for the disorder.

Likewise, the differences in EA indicate that individuals with TTM are more experientially avoidant and therefore, less psychologically flexible than controls. Although EA levels were elevated, EA did not significantly predict hair pulling severity; however, this finding may have been obscured by the underpowered analysis. These findings provide further support for the use of acceptance-enhanced therapies for TTM that target EA (cf. Woods et al., 2006). For example, a study of 404 participants with TTM found that elevated levels of dysfunctional cognitions about appearance, shame, and fear of negative evaluation, which are associated with hair pulling severity, diminished or disappeared after 
controlling for EA (Norberg et al., 2007). It appears that those with TTM have increased levels of EA and that this avoidance could be a potentially important mechanism of action in the treatment of the disorder. Moreover, the recent development of a TTM-specific version of the AAQ should assist further research on this topic (Houghton et al., 2014).

Although the role of acceptance-based therapies TTM treatment appears to be important, it is worth considering how much to focus on EA in the cases of primarily automatic pulling. This pulling style is habitual and typically occurs outside of one's awareness; therefore, the function of the behavior is less discernible. Automatic pulling behavior may operate through a different mechanism of action, requiring a treatment such as habit reversal training (Azrin \& Nunn, 1973). Improved assessment of those with TTM could identify whether an individual's pulling behavior is focused, automatic, or both, leading to the designation of a tailored treatment package. Some progress has been made in this area with the development of assessments of focused and automatic pulling behavior, such as the Milwaukee Inventory for Subtypes of Trichotillomania (Flessner et al. 2008). Additionally, combining habit reversal techniques with third wave behavior therapies, such as ACT and Dialectical Behavior Therapy, is gaining popularity and has shown promise as effective treatments (Keuthen et al., 2012, Twohig and Woods, 2004).

The TTM group scored higher on many of the clinical scales of the PAI related to psychopathology than the control group. As hypothesized and consistent with previous findings (Diefenbach et al., 2002, Schlosser et al., 1994, Christenson et al., 1992), the TTM group's anxiety, anxiety-related, depression, and borderline features scores were significantly higher than the control group. Differences were found for anxiety and anxiety-related disorders and each subscale, except traumatic stress. Individuals with TTM experience anxiety across various response modalities, including worry, rumination, tension, nervousness, and fatigue. Moreover, they appear to experience overt physiological signs of anxiety such as sweating, trembling, and shortness of breath. Of note, no significant differences were found in the levels of traumatic stress between the groups, indicating that individuals with TTM are not more distressed due to experiences of trauma than the general population. This finding provides some insight into previous studies that have suggested a potential relationship between TTM and early childhood trauma (Boughn and Holdom, 2003, Himle et al., 1995, Lochner et al., 2002). Although the potential exists for early childhood trauma to be associated with TTM, it appears that levels of distress due to trauma are not elevated in those with TTM. The notion that the presence of traumatic experiences is a precipitating event leading to the development of TTM is probably inaccurate. However, it is quite reasonable that traumatic experiences like other highly emotional experiences, can lead to a worsening of symptoms.

Regarding elevated levels of depression, the TTM group had experienced greater feelings of sadness, anhedonia, worthlessness, hopelessness and difficulty concentrating. However, physical functioning, activity, and sleep patterns were not significantly different than the control group. Those with TTM experienced elevated levels of borderline features related to affect instability and identity problems, as well as physical aggression and aggressive attitudes. This replicates the findings of previous research that demonstrated personality traits in those with TTM as being similar to those with borderline personality disorder (Hagh-shenas et al., 2004). Additionally, identity problems related to 
feelings of emptiness or lack of purpose could potentially be associated with the functional impairment seen in many individuals with TTM.

Regarding PAI treatment consideration scales, those with TTM had lower treatment rejection scale scores, indicating higher motivation for treatment. This finding is unsurprising, as individuals in the control group were specifically chosen because they lacked psychological symptoms and therefore, would have little reason to seek treatment. The TTM group also had higher stress and aggression scale scores than the control group. The elevated aggression and borderline features related to affect instability might be a result of the high level of impulsivity seen in the sample, such that those with TTM could be more reactive when encountering emotional content. The high stress scale score indicates a perception of living in a difficult or uncertain environment, which may be due to social impairment (Wetterneck, Woods, Norberg \& Begotka, 2006). The negative impression management scale, which was significantly elevated over the control group indicates a pessimistic worldview, but may also be related to a sense of shame, which has been theorized to be an important construct in TTM (Weingarden \& Renshaw, 2015), but has yet to be measured dimensionally. These findings suggest that individuals with TTM are often experiencing symptoms far beyond the scope of typical treatment for the disorder. For example, individuals with TTM who may also be experiencing elevated levels of anxiety and depression as well as possible aggression and borderline features would likely benefit from a more comprehensive treatment approach that is sensitive to these ancillary conditions. Current TTM treatment modalities could benefit from recognizing and better adapting to these additional conditions and personality traits.

The current study has some limitations. The sample had a notable lack of diversity with regard to race, ethnicity, and gender that could affect the generalizability. However, TTM is primarily a disorder found in females during adulthood (Chamberlain, Menzies, Sahakian, \& Fineberg, 2007), therefore, it is a small limitation. Still more examination of possible differentiation of symptomology and psychopathology with regard to race and ethnicity is needed. Also, the data for the TTM group and some of the non-TTM group were collected in different geographic locations. Although unlikely, there is potential for there to be differences in between the regions with regard to the measures included in the current study. Additionally, while the inclusion of individuals with Axis I disorders in the TTM group resulted in increased external validity, it also reduced internal validity. TTM is often accompanied with high rates of comorbidity, therefore, the current study's sample is more highly generalizable than if participants with only TTM were utilized. However, the decreased internal validity makes it impossible to conclude if the differences found between the treatment and control groups were related to TTM, the comorbid conditions, or some combination of the two. Additional studies with greater focus on internal validity are also needed to improve our understanding of what role comorbid conditions play in TTM and personality characteristics.

Finally, over 60 percent of the TTM group had comorbid diagnoses, while the control group had no clinical diagnoses. This difference allows for a baseline comparison of individuals with TTM to psychologically healthy individuals, however, the results are almost assuredly more elevated than would be seen if compared to a general population that included individuals with psychological pathology. Comparisons that examined potential differences between those with and without comorbid conditions in the TTM group revealed that comorbidity did not significantly contribute to 
differences in any of the measures of interest. Additionally, a post hoc analysis was performed to examine the scale that we expected to be most affected by comorbidity (i.e., depression). TTM participants with $(n=7)$ and without $(n=11)$ a comorbid depression diagnosis were compared with regard to the PAI depression scale and subscales. No significant differences were found between those with a diagnosis of depression and those without. While underpowered, this finding provides further evidence that comorbid conditions did not significantly affect comparisons between the TTM group that included comorbidity and the control group that did not.

In addition to addressing the limitations, we suggest that researchers consider other clinical variables hypothesized to be clinically important to TTM, such as feelings of shame and stigma (Wetterneck et al., 2006).

Despite these limitations, the current study provides valuable insight into the personality characteristics and comorbid psychopathology of individuals with TTM. These findings reveal that those with TTM are often suffering from various other clinically relevant psychological and personality concerns. These findings should inform and shape future treatment of TTM to be more comprehensive in its approach.

\section{Role of funding sources}

No funding was provided for this study.

\section{Conflict of interest}

All authors declare that they have no conflicts of interest.

\section{Acknowledgments}

None.

\section{References}

American Psychiatric Association, 2013. American Psychiatric Association. Diagnostic and statistical manual of mental disorders. (5th ed.), American Psychiatric Publishing, Arlington, VA (2013)

Azrin and Nunn, 1973. N.H. Azrin, R.G. Nunn. Habit-reversal: a method of eliminating nervous habits and tics. Behaviour Research and Therapy, 11 (4) (1973), pp. 619-628

Begotka et al., 2004. A.M. Begotka, D.W. Woods, C.T. Wetterneck. The relationship between experiential avoidance and the severity of trichotillomania in a nonreferred sample. Journal of Behavior Therapy and Experimental Psychiatry, 35 (1) (2004), pp. 17-24

Boughn and Holdom, 2003. S. Boughn, J.J. Holdom. The relationship of violence and trichotillomania. Journal of nursing scholarship, 35 (2) (2003), pp. 165-170

Chamberlan et al., 2007. S.R. Chamberlan, N.A. Fineberg, L.C. Blackwell, T.W. Robbins, B.J. Sahakian. A neuropsychological comparison of obsessive-compulsive disorder and trichotillomania. Neuropsychologia, 45 (2007), pp. 654-662

Chamberlain et al., 2007. S.R. Chamberlain, L. Menzies, B.J. Sahakian, N.A. Fineberg. Lifting the veil on trichotillomania. The American Journal of Psychiatry, 164 (4) (2007), pp. 568-574 
Chamberlain and Sahakian, 2007. S.R. Chamberlain, B.J. Sahakian. The neuropsychiatry of impulsivity. Current Opinion in Psychiatry, 20 (3) (2007), pp. 255-261

Christenson et al., 1992. G.A. Christenson, E. Chernoff-Clementz, B.A. Clementz. Personality and clinical characteristics in patients with trichotillomania. Journal of Clinical

Psychiatry, 53 (11) (1992), pp. 407-412

Diefenbach et al., 2002. G.J. Diefenbach, S. Mouton-Odum, M.A. Stanley. Affective correlates of trichotillomania. Behaviour Research and Therapy, 40 (11) (2002), pp. 1305-1315

Duke et al., 2009. D.C. Duke, D.K. Bodzin, P. Tavares, G.R. Geffken, E.A. Storch. The phenomenology of hairpulling in a community sample. Journal of Anxiety Disorders, 23 (8) (2009), pp. 1118-1125

Duke et al., 2010. D.C. Duke, M.L. Keeley, E.J. Ricketts, G.R. Geffken, E.A. Storch. The phenomenology of hairpulling in college students. Journal of Psychopathology and Behavioral Assessment, 32 (2) (2010), pp. 281-292

Flessner et al., 2012. C.A. Flessner, V.S. Knopik, J. McGeary. Hair pulling disorder (trichotillomania): genes, neurobiology, and a model for understanding impulsivity and compulsivity. Psychiatry research, 199 (3) (2012), pp. 151-158

Flessner et al., 2008.

C.A. Flessner, D.W. Woods, M.E. Franklin, S.E. Cashin, N.J. Keuthen, T.L.C.S.A. Board. The Milwaukee inventory for subtypes of trichotillomania-adult version (MIST-A): development of an instrument for the assessment of "focused" and "automatic" hair pulling. Journal of Psychopathology and Behavioral Assessment, 30 (1) (2008), pp. 20-30

Hagh-Shenas et al., 2004. H. Hagh-Shenas, A. Moradi, G. Dehbozorgi, B. Farashbandi, F. Alishahian.

Trichotillomania-associated personality characteristics. Iranian Journal of Medical

Sciences, 29 (3) (2004), pp. 105-108

Hayes et al., 2004.

S.C. Hayes, K.D. Strosahl, K.G. Wilson, R.T. Bissett, J. Pistorello, D. Toarmino, S.M. McCurry. Measuring experiential avoidance: a preliminary test of a working model. The Psychological Record, 4 (2004), pp. 553-578

Hayes et al., 1996. S.C. Hayes, K.G. Wilson, E.V. Gifford, V.M. Follette, K. Strosahl. Experiential avoidance and behavioral disorders: a functional dimensional approach to diagnosis and treatment. Journal of Consulting and Clinical Psychology, 64 (1996), pp. 1152-1168

Himle et al., 1995. J.A. Himle, P.S. Bordnick, B.A. Thyer. A comparison of trichotillomania and obsessive-compulsive disorder. Journal of Psychopathology and Behavioral Assessment, 17 (3) (1995), pp. 251-260

Houghton et al., 2014.

D.C. Houghton, S.N. Compton, M.P. Twohig, S.M. Saunders, M.E. Franklin, A.M. NealBarnett, D.W. Woods. Measuring the role of psychological inflexibility in Trichotillomania. Psychiatry Research, 220 (1) (2014), pp. 356-361

Keuthen et al., 2012.

N.J. Keuthen, B.O. Rothbaum, J. Fama, E. Altenburger, M.J. Falkenstein, S.E. Sprich, S.S. Welch. DBT-enhanced cognitive-behavioral treatment for trichotillomania: a randomized controlled trial. Journal of Behavioral Addictions, 1 (3) (2012), pp. 106-114

Keuthen et al., 1995.

N.J. Keuthen, R.L. O'Sullivan, J.N. Ricciardi, D. Shera, C.R. Savage, A.S. Borgmann, M.A. Jenike, L. 
Baer. The Massachusetts General Hospital (MGH) Hairpulling Scale: 1. Development and factor analysis. Psychotherapy and Psychosomatics, 64 (1995), pp. 141-145

Keuthen et al., Keuthen, N.J., Tung, E.S., Altenburger, E.M., Blais, M.A., Pauls, D.L., \& Flessner, C.A. (in press). Trichotillomania and personality traits from the five-factor model. Revista Brasileira de Psiquiatria.

Lochner et al., 2002. C. Lochner, P.L. du Toit, N. Zungu-Dirwayi, A. Marais, J. van

Kradenburg, S. Seedat, D.J. Stein. Childhood trauma in obsessive-compulsive disorder, trichotillomania, and controls. Depression and Anxiety, 15 (2) (2002), pp. 66-68

Morey, 1991. L.C. Morey. Personality assessment inventory. Psychological Assessment

Resources, Odessa, FL (1991)

Norberg et al., 2007. M.M. Norberg, C.T. Wetterneck, D.W. Woods, C.A. Conelea. Experiential avoidance as a mediator of relationships between cognitions and hair-pulling severity. Behavior Modification, 31 (4) (2007), pp. 367-381

Patton et al., 1995. J.H. Patton, M.S. Stanford, E.S. Barratt. Factor structure of the Barratt Impulsiveness Scale. Journal of Clinical Psychology, 51 (1995), pp. 768-774

Schlosser et al., 1994. S. Schlosser, D.W. Black, N. Blum, R.B. Goldstein. The demography, phenomenology, and family history of 22 persons with compulsive hair pulling. Annals of Clinical Psychiatry, 6 (1994), pp. 147-152

Stein et al., 1995. D.J. Stein, L. Mullen, M.N. Islam, L. Cohen, C.M. de Caria, E. Hollander. Compulsive and impulsive symptomatology in trichotillomania. Psychopathology, 28 (1995), pp. 208-213

Twohig and Woods, 2004. M.P. Twohig, D.W. Woods. A preliminary investigation of acceptance and commitment therapy and habit reversal as a treatment for trichotillomania. Behavior Therapy, 35 (4) (2004), pp. 803-820

Weingarden and Renshaw, 2015. H. Weingarden, K.D. Renshaw. Shame in the obsessive compulsive related disorders: a conceptual review. Journal of Affective Disorders, 171 (2015), pp. 74-84

Wetterneck et al., 2006. C.T. Wetterneck, D.W. Woods, M.M. Norberg, A.M. Begotka. The social and economic impact of trichotillomania: results from two nonreferred samples. Behavioral Interventions, 21 (2) (2006), pp. 97-109

Woods et al., 2006. D.W. Woods, C.T. Wetterneck, C.A. Flessner. A controlled evaluation of acceptance and commitment therapy plus habit reversal for trichotillomania. Behaviour Research and Therapy, 44 (5) (2006), pp. 639-656 